\title{
Proteome analysis guided genetic engineering of Corynebacterium glutamicum S9114 for tween 40-triggered improvement in L-ornithine production
}

\author{
Yan Jiang ${ }^{1 \dagger}$, Ming-Zhu Huang ${ }^{2 \dagger}$, Xue-Lan Chen $^{2}$ and Bin Zhang ${ }^{1 *}$ (i)
}

\begin{abstract}
Background: L-ornithine is a valuable amino acid with a wide range of applications in the pharmaceutical and food industries. However, the production of L-ornithine by fermentation cannot compete with other methods, because of the low titers produced with this technique. Development of fermentation techniques that result in a high yield of L-ornithine and efficient strategies for improving L-ornithine production are essential.

Results: This study demonstrates that tween 40 , a surfactant promoter of the production of glutamate and arginine, improves L-ornithine production titers in engineered C. glutamicum S9114. The intracellular metabolism under tween 40 triggered fermentation conditions was explored using a quantitative proteomic approach, identifying 48 up-regulated and 132 down-regulated proteins when compared with the control. Numerous proteins were identified as membrane proteins or functional proteins involved in the biosynthesis of the cell wall. Modulation of those genes revealed that the overexpression of CgS9114_09558 and the deletion of CgS9114_13845,_CgS9114_02593, and CgS9114_02058 improved the production of L-ornithine in the engineered strain of C. glutamicum Orn8. The final strain with all the exploratory metabolic engineering manipulations produced $25.46 \mathrm{~g} / \mathrm{L}$ of L-ornithine, and a yield of $0.303 \mathrm{~g}$ L-ornithine per g glucose, which was 30.6\% higher than that produced by the original strain ( $19.5 \mathrm{~g} / \mathrm{L})$.
\end{abstract}

Conclusion: These results clearly demonstrate the positive effect of tween 40 addition on L-ornithine accumulation. Proteome analysis was performed to examine the impact of tween 40 addition on the physiological changes in $C$. glutamicum Orn8 and the results showed several promising modulation targets for developing L-ornithine-producing strains.

Keywords: Corynebacterium glutamicum, Tween 40, L-ornithine, Metabolic engineering

\section{Background}

L-ornithine is a valuable non-protein amino acid that is an intermediate metabolite involved in the urea cycle. It

\footnotetext{
*Correspondence: zhangbin2919@163.com

${ }^{\dagger}$ Yan Jiang and Ming-Zhu Huang authors contribute equal to this work ${ }^{1}$ College of Bioscience and Engineering, Jiangxi Engineering Laboratory for the Development and Utilization of Agricultural Microbial Resources, Jiangxi Agricultural University, Nanchang 330045, China

Full list of author information is available at the end of the article
}

has numerous biological functions such as the treatment of liver disease, the promotion of wound healing, and it also plays a role in the anti-aging process [1]. Due to its various advantages in human physiological functions and widespread application in the pharmaceutical and food industries, the global L-ornithine market has seen rapid development in recent years [2]. Currently, the industrial production of L-ornithine is primarily depending on enzyme-catalyzed arginine hydrolysis and microbial fermentation [3]. Developing an efficient microbial cell

c) The Author(s) 2020. This article is licensed under a Creative Commons Attribution 4.0 International License, which permits use, sharing, adaptation, distribution and reproduction in any medium or format, as long as you give appropriate credit to the original author(s) and the source, provide a link to the Creative Commons licence, and indicate if changes were made. The images or other third party material in this article are included in the article's Creative Commons licence, unless indicated otherwise in a credit line to the material. If material is not included in the article's Creative Commons licence and your intended use is not permitted by statutory regulation or exceeds the permitted use, you will need to obtain permission directly from the copyright holder. To view a copy of this licence, visit http://creativeco mmons.org/licenses/by/4.0/. The Creative Commons Public Domain Dedication waiver (http://creativecommons.org/publicdomain/ zero/1.0/) applies to the data made available in this article, unless otherwise stated in a credit line to the data. 
factory to produce L-ornithine is a promising approach owing to its advantages in low-cost, sustainability, and environment friendly. Regarding current work in this field, it is important to point out that there are increasing in number of engineered strains, such as Escherichia coli [4], Saccharomyces cerevisiae [5], and Corynebacterium glutamicum [6], that have been modulated for L-ornithine production. $E$. coli is a model microbe with the advantages of having an explicit genetic background, a superior propagation speed, and convenient gene manipulation tools that have been employed for producing $\mathrm{L}$-ornithine by rational modulation of the urea cycle and optimizing the fermentation process [4]. However, E. coli fermentation inevitably results in the synthesis of endotoxin [7], a toxic substance that limits its application in the fermentation production of L-ornithine. S. cerevisiae is a superior eukaryotic microbial cell factory that has been defined as a 'Generally Recognized As Safe' (GRAS) strain which exhibits a high tolerance to harsh growing conditions and can be used to produce numerous valuable chemicals [8-10]. Modularized metabolic engineering strategies including the transformation of the carbon source transport system, the transformation of the central metabolic pathway, the assimilation and dissimilation of ammonia, and the energy supply and transfer of small molecular compounds were all processed in S. cerevisiae to produce L-ornithine [5]. However, the obtained production titer of L-ornithine by using $S$. cerevisiae as chassis microorganism is still in the preliminary stage and far away from the requirements of industrialization. For producing L-ornithine, C. glutamicum occupies the dominant position [11].

Corynebacterium glutamicum is a promising GRAS gram-positive bacterium that was intensively engineered to utilize a broad spectrum of carbon sources for the overproduction of numerous chemicals [12-14]. Currently, several studies have attempted to develop metabolically engineered strains that are able to rapidly convert a certain amount of glucose, or other alternative carbon resource, into L-ornithine. The biosynthesis pathway of L-ornithine in C. glutamicum is described in previous studies [15-18]. Jensen et al. [19] developed an L-ornithine producing C. glutamicum strain ORN6 through rational engineering, including the deletion of $\arg F, \arg R$, and $\arg G$, enhancing the supplement of glutamate via the optimized expression of $g d h$, redirection of the metabolic flux to the pentose phosphate pathway to provide adequate cofactor NADPH via a change of the start codon of pgi, overexpression of a feedback insensitive $\mathrm{N}$-acetylglutamate kinase, and the insertion of a second copy of the $\arg C J B^{M} D$ operon into the chromosome, resulting in the production of L-ornithine with a yield of $0.52 \mathrm{~g}$ of L-ornithine per g glucose. Kim et al. [6] constructed an engineered $C$. glutamicum strain through the deletion of $\operatorname{argF}$, proB, and $\operatorname{argR}$, plasmid-based overexpression of the $\operatorname{argCJBD}$ genes from C. glutamicum ATCC 21831, as well as the redirection of the carbon flux towards the pentose phosphate pathway via the modulated expression of $p g i, z w f$, and tkt operons that produced $51.5 \mathrm{~g} / \mathrm{L}$ of L-ornithine with a yield of $0.256 \mathrm{~g} / \mathrm{g}$ glucose in a 6.6-L fermenter. Jiang et al. [20] created an engineered strain by systematically manipulating L-ornithine metabolism and adaptive evolution that produced $24.1 \mathrm{~g} / \mathrm{L}$ of L-ornithine in a 5-L bioreactor. Shu et al. [21] performed an experiment that involved blocking the competing branch of the L-ornithine synthesis pathway, the site-directed mutagenesis of ornithine acetyltransferase, and the heterologous overexpression of the genes $\operatorname{argA}$ from E. coli and $\operatorname{argE}$ from Serratia marcescens in an L-arginine hyper-producing strain of Corynebacterium crenatum. This resulted in an engineered strain of Cc-QF-4, which produced $40.4 \mathrm{~g} / \mathrm{L}$ of L-ornithine with a yield of $0.269 \mathrm{~g} / \mathrm{g}$ glucose in a 5 -L bioreactor.

Polyoxyethylene sorbitan monopalmitate (Tween 40), a fatty acid ester surfactant, is widely employed as a fermentation trigger for industrial fermentation [22]. In $C$. glutamicum, the addition of tween 40 cannot only redirect the carbon flux towards the biosynthesis of glutamate by reducing the enzyme activity of $\alpha$-ketoglutarate dehydrogenase, but can also promote the secretion of glutamate by enhancing membrane permeability [23]. Addition of tween 40 is able to change the rigid membrane caused by inducement of excess biotin, a critical factor affecting the performance of glutamate fermentation in biotin auxotrophic C. glutamicum, which stimulate glutamate overproduction. In addition, the effect of fermentation promotion by tween 40 has been assessed in biotin auxotrophic C. glutamicum for the production of several products including L-glutamate, L-arginine [24], gamma-amino butyric acid [25], oleic acid [26], and 1,5-diaminopentane [27], whereas no studies have reported the effect of tween 40 on L-ornithine fermentation.

In a previous study, we systematically developed an engineered strain of $C$. glutamicum S9114 through the deletion of $\operatorname{argF}, n c g l 1221$, $\operatorname{argR}$, and putP, the attenuation of $\operatorname{odh} A$, and the overexpression of $\operatorname{argCJBD}$, which produced up to $19 \mathrm{~g} / \mathrm{L}$ of $\mathrm{L}$-ornithine in a shaker flask culture $[15,16]$. In the present study, the effects of tween 40 on L-ornithine production were investigated. In addition, differentially expressed proteins, triggered by adding tween 40, were identified using a total proteomics analysis. Furthermore, the effects of overexpressing some of the upregulated proteins and deleting a few of the downregulated proteins on L-ornithine accumulation were evaluated. 


\section{Results}

\section{Effect of tween $\mathbf{4 0}$ on L-ornithine production in C. glutamicum}

Tween 40 is a fermentation accelerator that is commonly used to produce L-glutamate in C. glutamicum when excessive biotin leads to an impermeable cell membrane. As previously reported, addition of tween 40 during the logarithmic period cannot only induce glutamate overproduction, but can also improve L-arginine production in C. crenatum by reforming cell surface structures and reducing the enzyme activity of $\alpha$-oxoglutarate dehydrogenase. Theoretically, addition of tween 40 can promote the biosynthesis of L-ornithine by redirecting the carbon flux from the tricarboxylic acid cycle to glutamate accumulation or improving membrane permeability in $C$. glutamicum. To further characterize the effect of tween 40 on L-ornithine production, we optimized the addition concentration and addition phase during fermentation of the strain C. glutamicum Orn8. Results after $40 \mathrm{~h}$ of $C$. glutamicum Orn8 fermentation using a shake flask suggests that the production titer was significantly affected by the temporal points of filtration degermed tween 40 addition, and cell growth was also reduced when the temporal points of filtration degermed tween 40 addition was less than $6 \mathrm{~h}$ (Fig. 1a). The yield of L-ornithine was not further improved by optimizing the addition concentration of tween 40 from $1 \mathrm{~g} / \mathrm{L}$ to $9 \mathrm{~g} / \mathrm{L}$ (Fig. 1b). Consequently, the highest L-ornithine production titer $(14.4 \pm 0.64)$ was obtained by using an $8 \mathrm{~h}$ temporal points of tween 40 addition and an addition concentration of $5 \mathrm{~g} / \mathrm{L}$, which is $33.3 \%$ higher than that of the control without the addition of tween $40(10.8 \mathrm{~g} / \mathrm{L})$. The significance of this finding rests on the fact that the addition of Tween 40 significantly improved L-ornithine production in the engineered strain of C. glutamicum Orn8.

\section{MS identification of differentially expressed proteins induced by tween $\mathbf{4 0}$}

Although the addition of tween 40 can increase the production titer of L-ornithine, the specific mechanisms of action in strain C. glutamicum Orn8 have not been fully elucidated. To gain further insight into the involvement of adding tween 40 during the logarithmic phase on the physiological mechanisms of C. glutamicum Orn8, a quantitative proteomics assay using stable isotope dimethyl labeling was processed to identify the up and down regulated proteins. Three biological repetitions were employed to ensure the accuracy of the experimental data in differentially expressed proteins. A total of 2237 proteins were identified in this study, of which 2138 contained quantitative information (Additional file 1). If 1.2-fold was taken as the minimum change threshold and a $t$ test $\mathrm{p}$-value $<0.05$ as the standard, 180 proteins were recognized with expression alternation from mass spectrometry identification results (Additional file 2). Among them, 48 proteins were overexpressed, whereas 132 proteins were downregulated after the cell was exposed to tween 40 in the engineered strain of C. glutamicum Orn8. The subcellular location analysis of these differentially expressed proteins suggests that 95 proteins $(52.78 \%)$ were functioning in the cytoplasm, 42 proteins (23.33\%) were functioning on the cell membrane, 42 proteins $(23.33 \%)$ were functioning in the extracellular matrix, and only one protein functioned in the cell wall (Fig. 2a). Subsequently, the molecular functions of these differentially expressed proteins were classified by GO annotations, and are mainly involved in 4 iron, 4 sulfur cluster binding, metal cluster binding, acetolactate synthase activity, radical SAM enzyme activity, ligase activity, forming phosphoric ester bonds, and calcium ion binding (Fig. 2b). Particularly, the expression of $n c g l 1273$
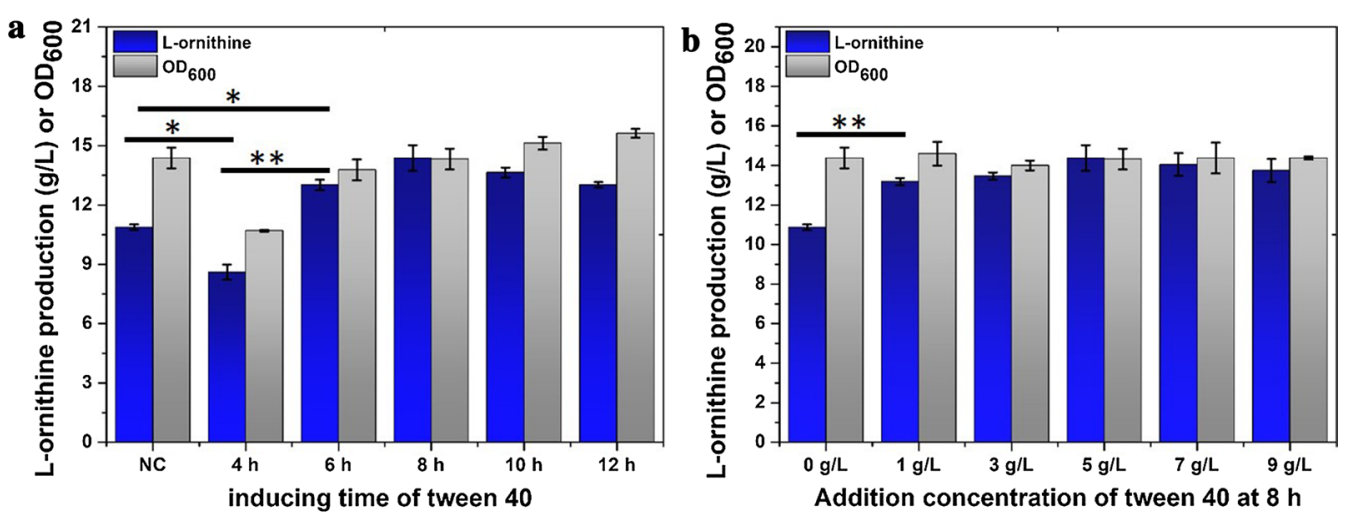

Fig. 1 Effect of tween 40 addition on cell growth and L-ornithine production. a Optimizing the temporal points of tween 40 addition. b Optimizing tween 40 addition concentration. Gray bar represents $\mathrm{OD}_{600}$, blue bar represents L-ornithine concentration. Results of standard deviations present in three individual experiments. ${ }^{*} \mathrm{P}<0.05,{ }^{* *} \mathrm{P}<0.01$ 


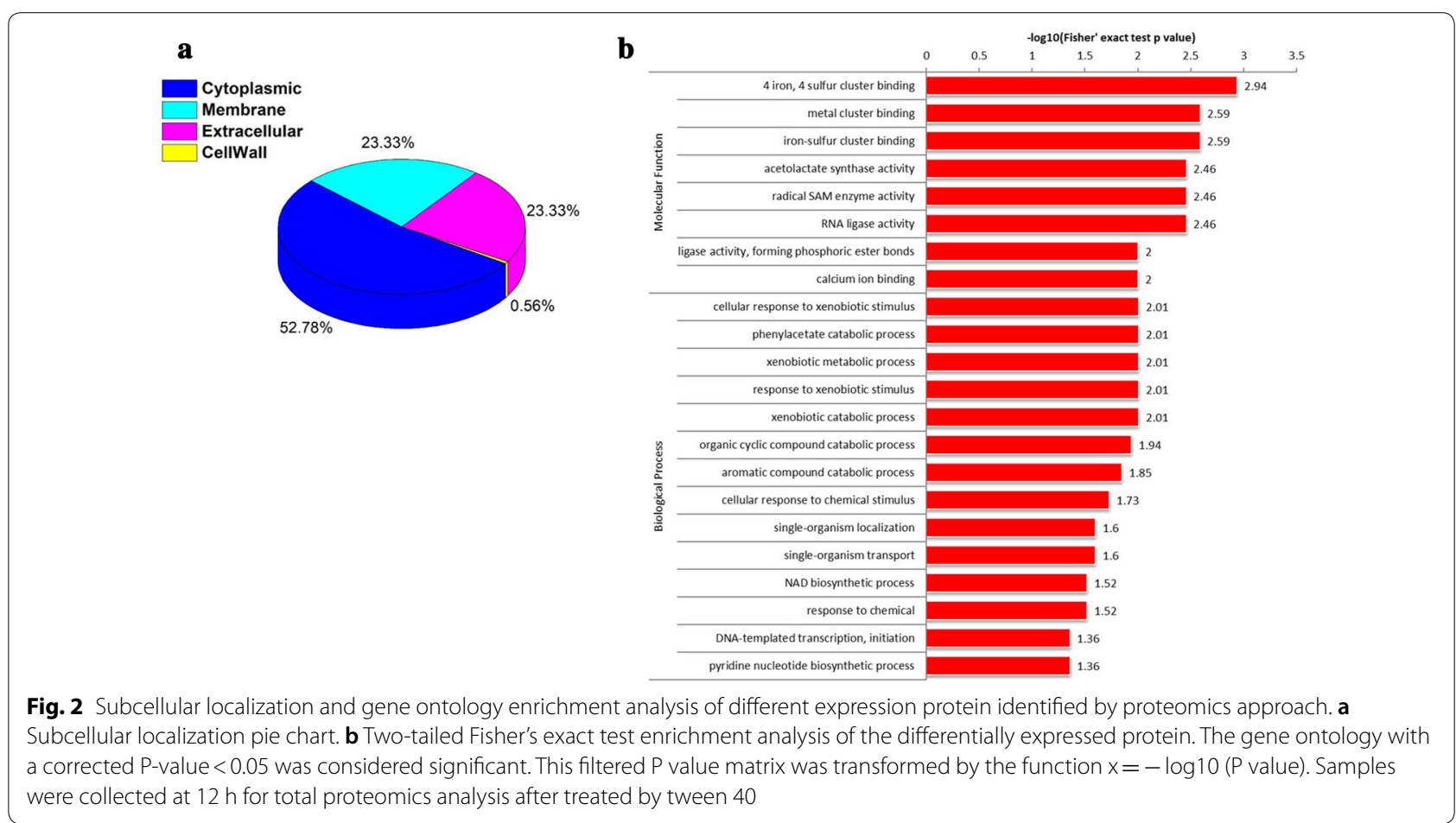

( $d t s R 2)$, encoding an acetyl-CoA carboxylase biotin carboxyl carrier protein subunit, was downregulated by 1.22-fold, and the expression of CgS9114_13431 (dtsR1), encoding an acetyl-CoA carboxyltransferase, was downregulated by 1.66 -fold, suggesting that the fatty acid synthesis pathway was weakened by the addition of tween 40 in the strain of C. glutamicum Orn8. In addition, the biological processes of these differentially expressed proteins were mainly involved in the cellular response to xenobiotic stimulus, the phenylacetate catabolic process, the organic cyclic compound catabolic process, the aromatic compound catabolic process, the cellular response to chemical stimulus, the NAD biosynthetic process, and the pyridine nucleotide biosynthetic process. Furthermore, results of KEGG enriched analysis indicated that the cytoplasmic upregulated proteins were mainly listed on the metabolic pathway of C5-branched dibasic acid metabolism, the phosphotransferase system, branched amino acid biosynthesis, thiamine metabolism, fructose and mannose metabolism, pantothenate and CoA biosynthesis, butanoate metabolism, nicotinate and nicotinamide metabolism, and 2-oxocarboxylic acid metabolism (Fig. 3a). The downregulated proteins were mainly involved in phenylalanine metabolism, monobactam biosynthesis, and $\beta$-alanine metabolism (Fig. 3b). Interestingly, bioB encoding a biotin synthase, bioN encoding a biotin transport system permease protein, and bioM encoding a biotin transport system ATP-binding protein were attenuated by $1.22,1.30$, and 1.33 -fold, respectively, which indicated that the biosynthesis pathway of biotin was affected by the presence of tween 40 . Detailed protein information is presented in the supporting materials (Additional files 1, 2) Taken together, these differentially expressed proteins triggered by the addition of tween 40 cover a wide range of metabolic and physiological processes.

Effect of overexpressing upregulated membrane proteins induced by tween $\mathbf{4 0}$ addition on L-ornithine production As previously demonstrated, tween 40 addition reduced $\alpha$-oxoglutarate dehydrogenase by downregulating the expression of $d t s R 1$, a subunit of acetyl-CoA carboxylase, which improved the production titer of $\mathrm{L}$-arginine by $16.5 \%$ in C. crenatum [24]. Theoretically, attenuation of acetyl-CoA carboxylase exhibits three functional mechanisms for glutamate-derived compounds overproduction, such as reducing the $\alpha$-oxoglutarate dehydrogenase activity that converts the metabolic fluxes into the L-glutamate biosynthetic pathway, providing more cofactor acetyl-CoA for the biosynthesis of $\mathrm{N}$-acetylglutamate by attenuating the conversion from acetyl-CoA to malonyl-CoA, and improving membrane permeability by reducing the biosynthesis of phospholipids. From the results of a quantitative proteomics assay, dtsR1 was identified and downregulated by tween 40 addition. To further substantiate the role of 


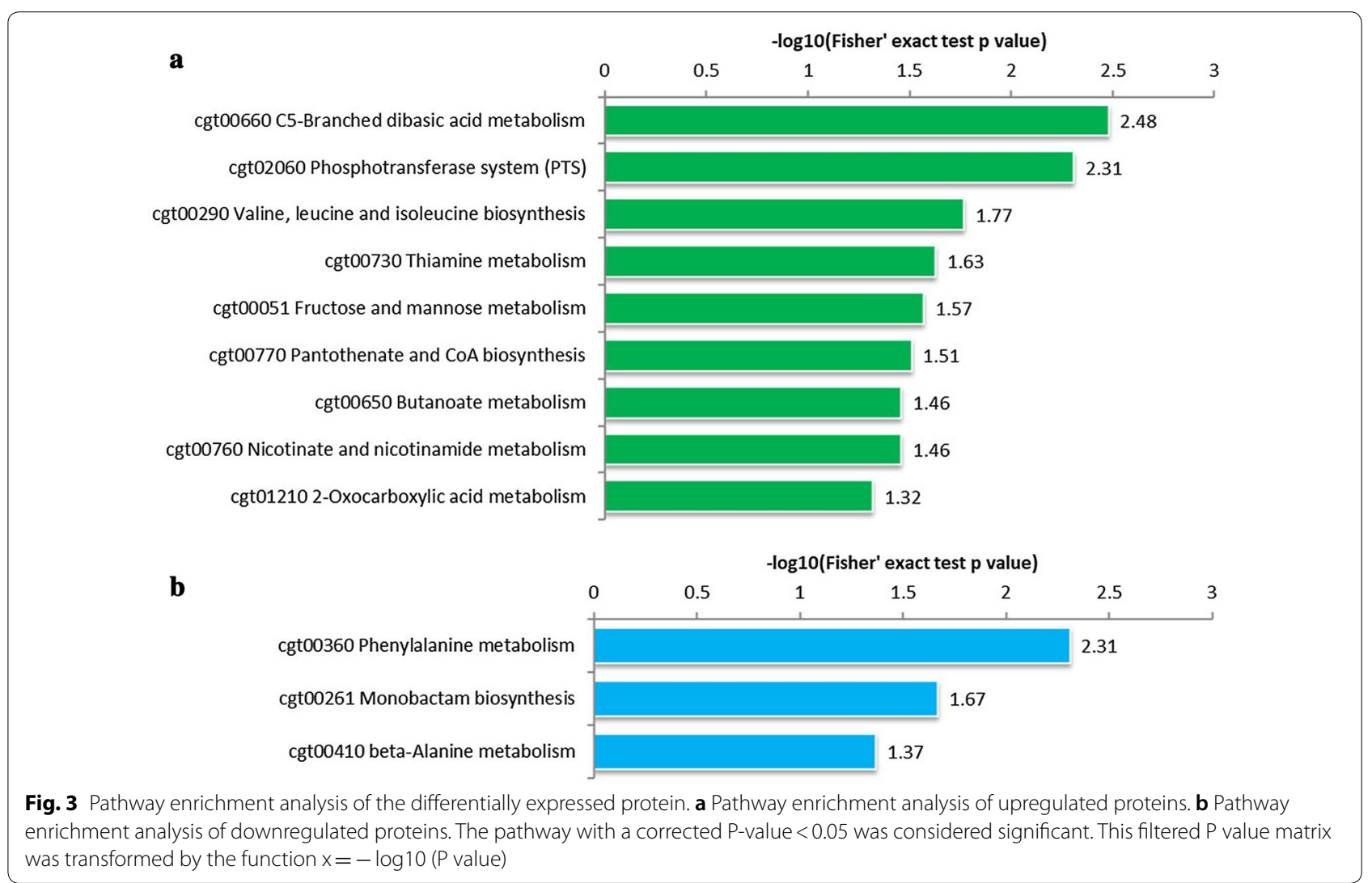

dtsR1 on L-ornithine accumulation, we attempted to attenuate its expression using gene deletion, an RBS change, the insertion of a terminator, and by adding a C-terminal degradation label of ASV or AAV in the strain of C. glutamicum Orn8 by using a homologous recombination technique. Unfortunately, no positive recombinant strains were found on the plate, suggesting that $d t s R 1$ is necessary for cell growth and cannot be weakened in C. glutamicum Orn8 (data not shown). The original aim of this study was to find efficient targets for improving L-ornithine production. Thus, we attempted to overexpress proteins that were upregulated by more than two-fold compared to the control (shown in Table 1). An E. coli-C. glutamicum shuttle expression plasmid pEC-XK99E was used for the expression of CgS9114_09563, CgS9114_14252, CgS9114_09558, CgS9114_04075, and CgS9114_11142. However, only pEC-CgS14252 and pEC-CgS09558 were successfully overexpressed in the strain of C. glutamicum Orn8, and thus generated the strains Orn18 and Orn19. Overexpression of the other three genes was probably toxic to the cell and led to mutant clones that were not viable. The empty plasmid pEC-XK99E was also introduced to $C$. glutamicum Orn 8 and generated strain Orn 17 as control. Result of 72 h shake flask cultivation revealed that strain Orn 19 produced $20.28 \pm 0.5275 \mathrm{~g} / \mathrm{L}$ of L-ornithine which is $15 \%$ higher than that of the control strain Orn17(17.66 \pm 0.3587$)$, and strain Orn18 produced an approximately equal amount of L-ornithine $(17.81 \pm 0.6752)$ as compared with the control strain Orn17 (Fig. 4a; Table 2). In addition, the cell growth was not affected by the plasmid-based overexpression of CgS9114_14252 and CgS9114_09558 (Fig. 4b). To further elucidate the role of CgS9114_14252 and CgS9114_09558 on L-ornithine accumulation, we inserted a strong $\mathrm{P}_{t a c}$ promoter in the upstream region of each gene, which resulted in strains Orn20 and Orn21. As expected, strain Orn20 harboring CgS9114_09558 overexpression produced $12.8 \%$ more L-ornithine than that of the control strain Orn8, while strain Orn21 produced an equal concentration of L-ornithine as the control strain Orn8 (Fig. 4c, d). Taken together, these results illustrate that overexpression of CgS9114_09558 promotes L-ornithine production in mutant $\bar{C}$. glutamicum Orn8, although the biological function has not been fully elucidated. 
Table 1 Two-fold above differentially expressed proteins identified by bioinformatic analysis

\begin{tabular}{|c|c|c|c|c|c|c|}
\hline Uniprot no. & Name & Description & Fold change & P-value & Regulated type & Protein MW [kDa] \\
\hline UPI0001335099 & CgS9114_09563 & Membrane protein & 7.256 & $1.4154 \mathrm{E}-06$ & Up & 30.261 \\
\hline UPI0000165D0A & CgS9114_14252 & $\begin{array}{l}\text { Thiamin-regulated hydroxymethyl- } \\
\text { pyrimidine ECF transporter }\end{array}$ & 4.397 & 0.00076343 & Up & 21.047 \\
\hline UPI0001335098 & CgS9114_09558 & $A B C$ transporter & 3.364 & 0.00023894 & Up & 33.102 \\
\hline UPI0002230CC7 & CgS9114_04075 & Sugar/inositol transporter & 2.42 & 0.0037017 & Up & 53.663 \\
\hline UPI00000B98E2 & CgS9114_11142 & RNA polymerase sigma-70 & 2.285 & 0.00149636 & Up & 37.573 \\
\hline UPI00013356FF & CgS9114_11567 & Hypothetical protein & -2 & 0.00016463 & Down & 12.641 \\
\hline UPI0002233099 & CgS9114_12732 & Hypothetical protein & -2.079 & 0.035118 & Down & 19.917 \\
\hline UPI000003A2AE & CgS9114_13171 & Transcription factor WhiB & -2.141 & $1.96915 \mathrm{E}-05$ & Down & 9.5859 \\
\hline UPI0002233056 & CgS9114_12442 & Peptidoglycan recognition protein & -2.188 & $2.4755 \mathrm{E}-05$ & Down & 71.159 \\
\hline UPI0002232B52 & CgS9114_00255 & Calcium ion binding & -2.32 & $2.6369 \mathrm{E}-06$ & Down & 90.876 \\
\hline UPI000223314F & CgS9114_13516 & Hypothetical protein & -2.32 & 0.00036372 & Down & 17.644 \\
\hline UPI0002230CB5 & CgS9114_01180 & Hypothetical protein & -2.387 & $2.155 \mathrm{E}-07$ & Down & 79.258 \\
\hline UPI000223195D & CgS9114_04917 & Hypothetical protein & -2.5 & 8.4307E-05 & Down & 18.129 \\
\hline UPI000223312F & CgS9114_13366 & Hypothetical protein & -2.584 & 0.0026047 & Down & 18.208 \\
\hline UPI00013350CF & CgS9114_09908 & Putative esterase & -2.611 & 3.4887E-06 & Down & 43.563 \\
\hline UPI0002230695 & CgS9114_09663 & Hypothetical protein & -2.653 & 0.00010412 & Down & 13.101 \\
\hline UPI00022330EE & CgS9114_13056 & Peptidase S1 & -2.924 & $1.99298 \mathrm{E}-05$ & Down & 36.882 \\
\hline UPI0002230696 & CgS9114_09668 & Hypothetical protein & -2.967 & 0.00058298 & Down & 13.194 \\
\hline UPI000223195B & CgS9114_04907 & Hypothetical protein & -3.058 & 0.00129914 & Down & 18.18 \\
\hline UPI000003A50D & CgS9114_14497 & Putative esterase & -3.378 & 3.5667E-05 & Down & 33.531 \\
\hline UPI0002231962 & CgS9114_04952 & Putative esterase & -3.401 & $2.0229 E-08$ & Down & 39.62 \\
\hline UPI000133536B & CgS9114_13715 & Putative secreted protein & -3.413 & $2.1044 \mathrm{E}-08$ & Down & 29.955 \\
\hline UPI000133510C & CgS9114_14352 & Hypothetical protein & -3.521 & 0.00018473 & Down & 24.492 \\
\hline UPI0001335576 & CgS9114_00220 & Ferredoxin-NADP+ reductase & -3.597 & $5.1049 \mathrm{E}-07$ & Down & 50.056 \\
\hline UPI000223193A & CgS9114_01878 & protein prenyltransferase & -3.774 & $6.0916 \mathrm{E}-07$ & Down & 40.614 \\
\hline UPI0002231C7B & CgS9114_02058 & L, D-transpeptidase & -3.817 & $3.7351 \mathrm{E}-07$ & Down & 26.282 \\
\hline UPI0002232E3D & CgS9114_06260 & Hypothetical protein & -3.953 & 3.3347E-09 & Down & 18.827 \\
\hline UPI0002231960 & CgS9114_04942 & Calcium-binding & -4.149 & 0.00013962 & Down & 18.34 \\
\hline UPI00022322E5 & CgS9114_02593 & Lipocalin & -4.762 & $3.0099 \mathrm{E}-06$ & Down & 23.181 \\
\hline UPI00013353A8 & CgS9114_13845 & Peptidase & -6.494 & 5.3207E-07 & Down & 24.359 \\
\hline UPI0002231622 & CgS9114_01853 & Hypothetical protein & -8.065 & $1.6529 \mathrm{E}-07$ & Down & 21.665 \\
\hline
\end{tabular}

\section{Improvement of L-ornithine production by the deletion} of the downregulated proteins

As can be seen in Table 1, the addition of tween 40 not only stimulated the expression of CgS9114_09563, CgS9114_14252, CgS9114_09558, CgS9114_04075, and CgS9114_11142, but also inhibited the expression of numerous other genes. To further characterize the effect of these downregulated genes on L-ornithine production, we examined eight genes, including CgS9114_13845, CgS9114_02593, CgS9114_02058, CgS9114_14352, CgS9114_04952, CgS9114_14497, CgS9114_01853, and CgS9114 04942, which had the highest expression fold changes, using gene deletion assays. Among them, only six genes were successfully deleted, which generated the recombinant strains Orn22, Orn23, Orn24, Orn25, Orn26, and Orn27. As shown in Fig. 5a, d, strain
Orn22 with the deletion of CgS9114_13845, Orn23 with the deletion of CgS9114_02593, and Orn24 with the deletion of CgS9114_02058 produced $22.51 \pm 0.4853$, $21.86 \pm 0.0844$, and $21.8421 \pm 0.9073 \mathrm{~g} / \mathrm{L}$ of L-ornithine after $72 \mathrm{~h}$ of shake flask cultivation respectively, which is $15 \%, 11.6 \%$, and $11.5 \%$ higher than that $(19.5 \mathrm{~g} / \mathrm{L})$ of the original strain, Orn8 (Table 2). Nevertheless, strain Orn25 with the deletion of CgS9114_14352, Orn26 with the deletion of CgS9114_04952, and Orn27 with the deletion of CgS9114_14497 produced $18.87 \pm 0.5486$, $17.18 \pm 0.1688,16.93 \pm 0.422 \mathrm{~g} / \mathrm{L}$ of $\mathrm{L}$-ornithine respectively, which exhibits disparate degrees of decline in L-ornithine production titer when compared with the control strain, Orn8 (Table 2). Fortunately, the deletion of those genes exerts no obvious disturbance on cell growth or glucose consumption (Fig. 5b, c, e, f). In addition, the 

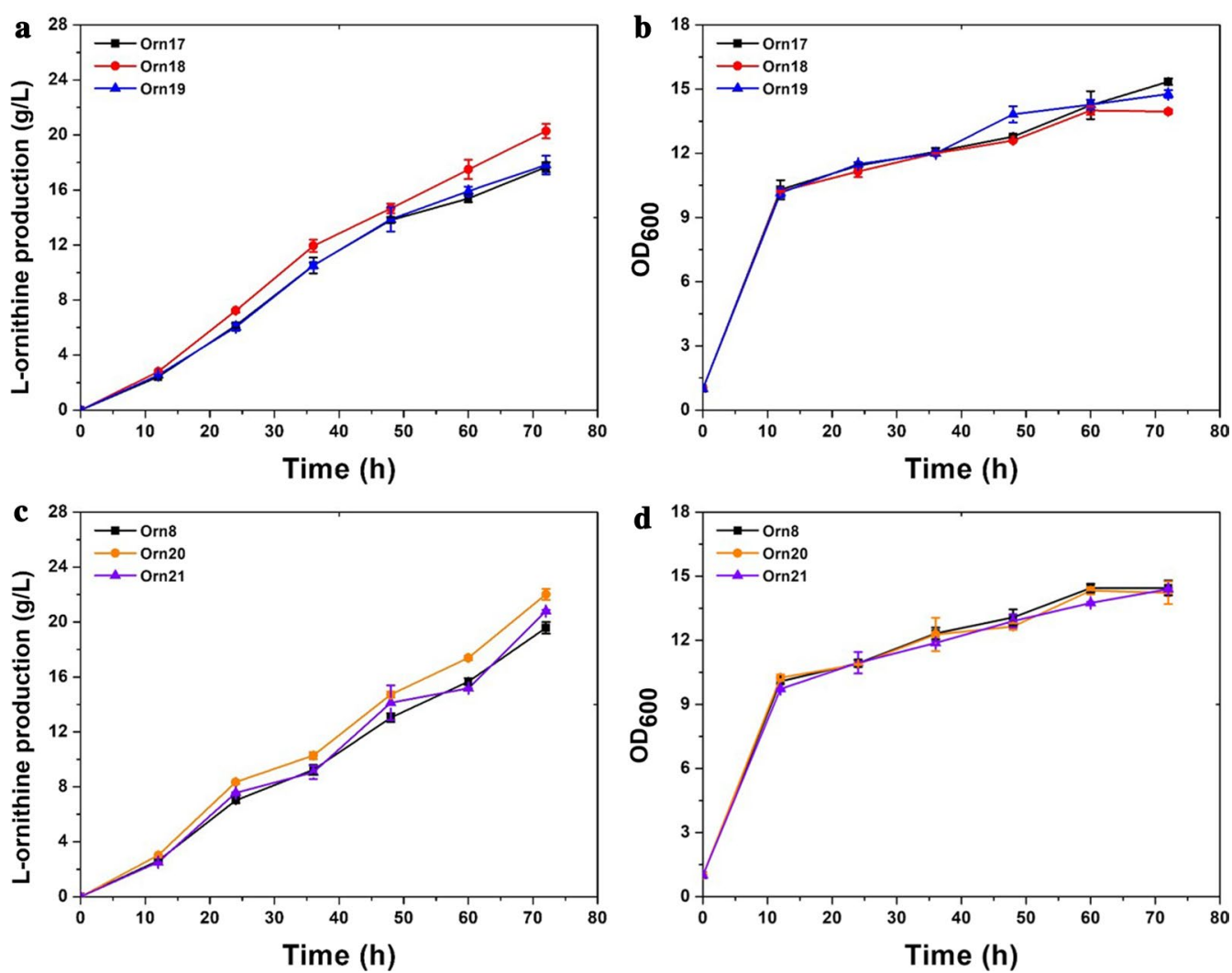

Fig. 4 Assessment of cell growth and L-ornithine productivity of strains Orn8, Orn17(Orn8 carrying empty plasmid pEC-XK99E), Orn18(Orn8 carrying expression plasmid pEC-CgS09558), Orn19 (Orn8 carrying expression plasmid pEC-CgS14252), Orn20 (Orn8 carrying $P_{\text {tac }}$ promoter inserted in the upstream region of CgS9114_09558), Orn21(Orn8 carrying $P_{\text {tac }}$ promoter inserted in the upstream region of CgS9114_14252). a L-ornithine production curves for strains Orn17, Orn18, and Orn19. b Cell growth curves for strains Orn17, Orn18, and Orn19. c L-ornithine production curves for strains Orn8, Orn20, and Orn21. b Cell growth curves for strains Orn8, Orn20, and Orn21. Samples were collected per $12 \mathrm{~h}$ for fermentation parameter determination. Data represent average values and standard deviations from three individual experiments

synergistic effect of three positive targets was also investigated using combinational modulation, which resulted in strain Orn28, Orn29, and Orn30. As illustrated in Fig. 6a, an engineered strain of Orn28 harboring a double deletion of CgS9114_13845 and CgS9114_02593 produced $23.83 \pm 0.1892 \mathrm{~g} / \mathrm{L}$ of $\mathrm{L}$-ornithine with a yield of $0.287 \mathrm{~g}$ of ornithine per g of glucose (Table 2). Furthermore, Orn29 with a triple deletion of CgS9114_13845, CgS9114_02593, and CgS9114_02058 produced $25.46 \pm 0.2270 \mathrm{~g} / \mathrm{L}$ of L-ornithine with a yield of $0.303 \mathrm{~g}$ of ornithine per $\mathrm{g}$ of glucose, which is $23 \%$ and $31 \%$ higher than that of the control strain of Orn8, respectively (Table 2). Combination modulation of these deletion targets exhibited an efficient synergistic effect on improving the yield of L-ornithine in strain Orn8 and exerts no negative effect on cell growth or glucose consumption (Fig. 6b, c). However, overexpression of CgS9114_09558 in strain Orn29 generated strain Orn30, and was not able to further promote L-ornithine accumulation. In conclusion, these results suggest that modulation of these targets derived from proteomics exhibit a positive synergistic effect on the biosynthesis of L-ornithine in C. glutamicum.

\section{Discussion}

In this study, we attempted a system-wide demonstration of the effect of adding tween 40 on L-ornithine production and examined its physiological mechanism in C. glutamicum Orn8. As anticipated, fermentation cultures treated with tween 40 during the logarithmic phase exhibited a significant improvement in L-ornithine production, which is consistent with previous work which reported that addition of tween 40 promoted the production of L-glutamate [28, 29] and L-arginine [30] in C. glutamicum. However, addition of tween 40 in the incipient fermentation period (as early as eight hours after the start of fermentation) resulted in a remarkable decline of the L-ornithine production titer that was likely due to the growth inhibition of tween 40, which was also reported in other C. glutamicum strains [31]. Our 

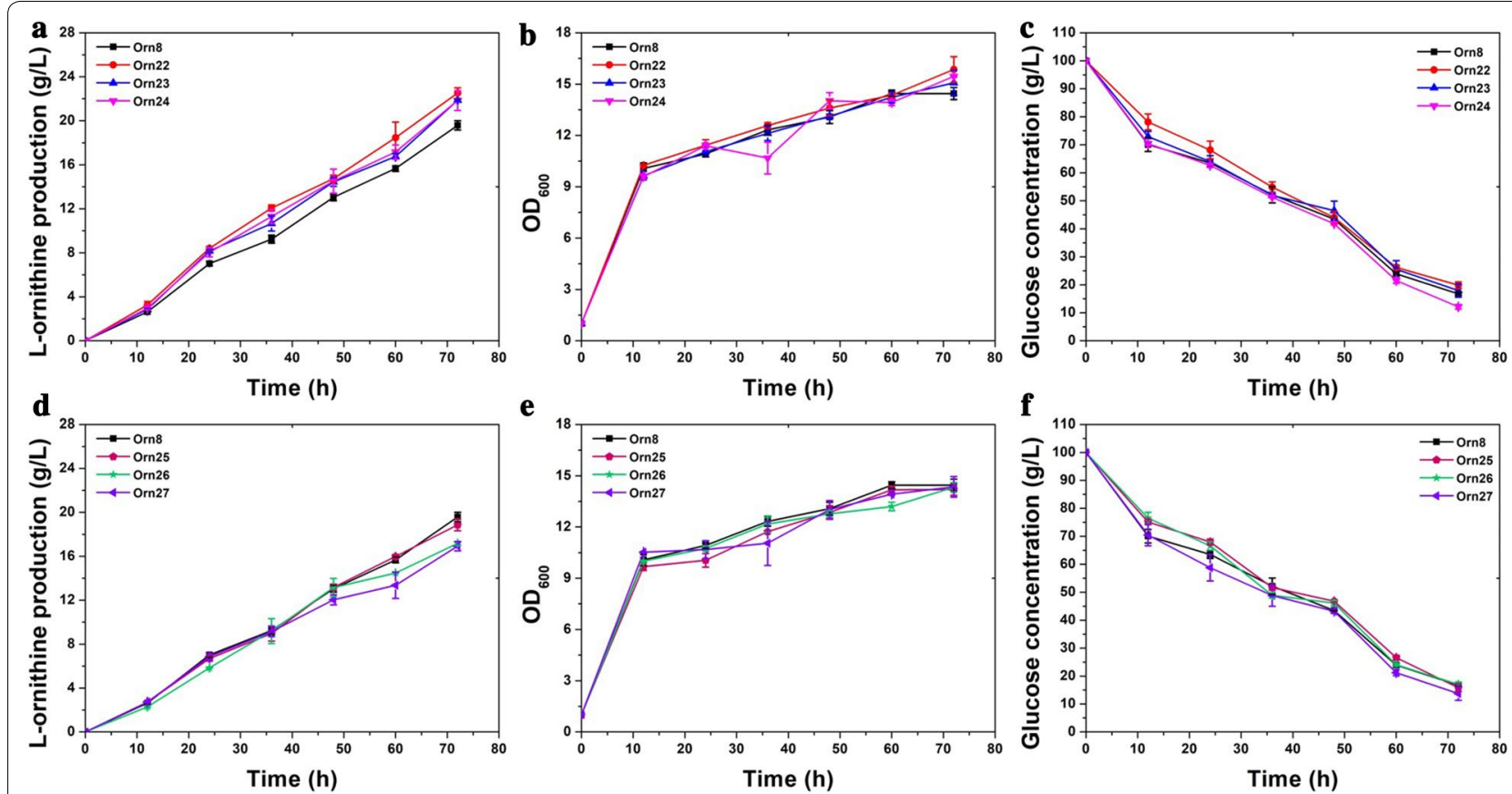

Fig. 5 Measurement of cell growth, L-ornithine productivity, and glucose consumption performed by strain Orn8, Orn22 (Orn8 with deletion of CgS9114_13845), Orn23 (Orn8 with deletion of CgS9114_02593), Orn24 (Orn8 with deletion of CgS9114_02058), Orn25 (Orn8 with deletion of CgS9114_14352), Orn26 (Orn8 with deletion of CgS9114_04952), Orn27 (Orn8 with deletion of CgS9114_14497). a L-ornithine production curves for strains Orn8 (black square), Orn22 (red circle), Orn23 (blue upper triangle), Orn24(pink lower triangle). b Cell growth of strain Orn8, Orn22, Orn23, and Orn24. c Residual glucose concentration curves of strain Orn8, Orn22, Orn23, and Orn24. d L-ornithine production curves for strains Orn8 (black square), Orn25 (dull-red pentagon), Orn26 (green pentacle), Orn27(purple left triangle). Samples were collected per $12 \mathrm{~h}$ for fermentation parameter determination. Data represent the average values and standard deviations from three individual experiments

observations suggest that the addition of tween 40 exerts a positive effect on L-ornithine accumulation, which provides an effective approach to reducing the production cost of L-ornithine. To further investigate the physical mechanism triggered in C. glutamicum Orn8 by adding the appropriate amount of tween 40, a total quantitative proteomics assay was performed and 180 proteins were discovered that exceeded a 1.2-fold expression change. Bioinformatics analysis of these proteins suggested that the overexpression of the thiamine synthesis pathway, attenuation of fatty acid synthesis pathway, and reduction of the biotin uptake system were putatively correlated with the improvement of the L-ornithine production titer induced by tween 40 addition. Thiamine is a component of the pyruvate dehydrogenase complex and converts pyruvate to acetyl-CoA, which is widely used for the production of various products including L-valine, 2-ketosiovalerate, pyruvate, succinate, and isobutanol [32]. Previous studies have identified AcetylCoA, an important cofactor, as a rate-limiting step for L-ornithine production by the deletion of the acetate biosynthesis pathway and by enhancing the glycolytic pathway [17]. Thus, it is generally accepted that the addition of tween 40 stimulates the supply of intracellular
acetyl-CoA by upregulating the thiamine synthesis pathway, thereby increasing the production of L-ornithine. In addition, the reduced expression of acetyl-CoA carboxylase, a biotin dependent enzyme encoded by $d t s R 1$ and $d t s R 2$, indicated that the biosynthesis of fatty acids was inhibited by tween 40 addition, which presumably leads to cell wall becomes more permeable by reducing the mycolic acid layer and provide abundant acetyl-CoA for the production of L-ornithine. It has been established that attenuating the expression of $d t s R 1$ was processed by tween 40 addition, which was consistent with previous work performed in C. crenatum which discovered that the addition of tween 40 inhibited the expression of $d t s R 1$ and stimulated L-arginine overproduction [24]. Furthermore, biotin is a cofactor of acetyl-CoA carboxylase involve in the biosynthesis of fatty acids. The excessive supply of biotin frequently leads to the production of a large amount of fatty acids which improved the thickness of the cell wall and hampered the secretion of glutamate [33, 34]. As discussed in previous studies, it was claimed that the addition of tween 40 or penicillin was able to change the rigid cell wall created by excess biotin via downregulation of the expression of $d t s R 1$, attenuating $\alpha$-oxoglutarate dehydrogenase activity, and inhibiting 

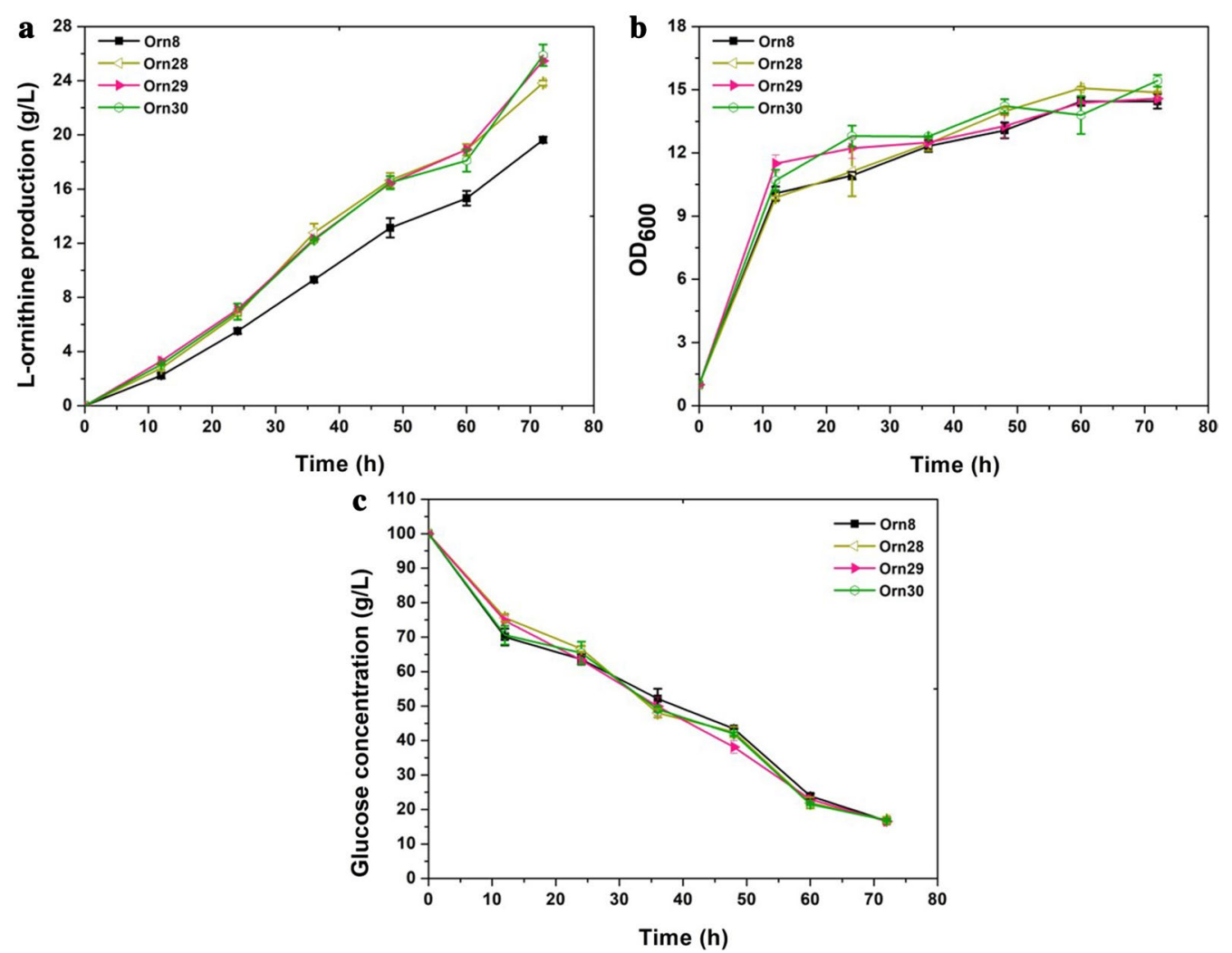

Fig. 6 Effect of combined modulating CgS9114_13845, CgS9114_02593, CgS9114_02058, and CgS9114_09558 on L-ornithine production. a L-ornithine production curves for strains Orn8 (black square), Orn28 (yellow left triangle) (Orn8 with deletion of CgS9114_13845 and CgS9114_02593), Orn29 (red right triangle) (Orn8 with deletion of CgS9114_13845, CgS9114_02593 and CgS9114_02058), Orn30 (green cycle) (Orn8 with deletion of CgS9114_13845, CgS9114_02593, and CgS9114_02058; overexpression of CgS9114_09558).b cell growth of those strains. c Residual glucose concentration curves of those strain. Samples were collected per $12 \mathrm{~h}$ for measuring fermentation parameter. Data represent the average values and standard deviations from three individual experiments

the biosynthesis of peptidoglycan which showed beneficial influences on the promotion of L-glutamate accumulation [35]. In addition to the reduced expression of $d t s R 1$, this study also found that the biotin uptake system composed of the bioYMN operon was downregulated by tween 40 addition, which indicated that L-glutamate production that was induced by tween 40 under conditions with excessive biotin was probably due to the attenuation of the biotin uptake system.

To detect the presence of other unknown proteins associated with increased ornithine production, the effect of overexpressed proteins, which were upregulated by more than two-fold by tween 40 addition, on L-ornithine production was also examined in strain C. glutamicum Orn8. Overexpression of a putative $\mathrm{ABC}$ transporter, encoded by CgS9114_09558, which shows 3.3-fold upregulated expression, exerts a positive effect on L-ornithine accumulation, illustrating that this membrane is able to directly or indirectly contribute to the biosynthesis of L-ornithine. This observation reveals a novel transporter involved in L-ornithine production. However, Overexpression of the other genes, more than two-fold upregulated by tween 40 addition, was toxic to the cell growth, which is consist with the significant reduction of $\mathrm{OD}_{600}$ and L-ornithine production titer induced by addition of tween 40 prior to $6 \mathrm{~h}$ (Fig. 1). Those results further confirmed our previous work indicated that addition of tween 40 caused toxic effect on the cell growth of strain C. crenatum [24]. Notably, modulation of those genes with the highest expression change folds by tween 40 addition suggested that deleting CgS9114_13845, which encodes the phage peptidoglycan binding endopeptidase, CgS9114_02593 that encodes a lipocalin, and CgS9114_02058, which encodes an L, D-transpeptidase associated with the biosynthesis of cell wall, could promote the biosynthesis of L-ornithine. It can be speculated that modulating the expression of genes involved in cell wall formation enhanced the production titer of 
L-ornithine, which is consistent with a previous report that the inhabitation of transpeptidase caused by the addition of penicillin resulted in the improvement of cell permeability and L-glutamate overproduction [27].

\section{Conclusion}

The addition of fermentation triggers has been extensively studied for its ability to promote the production of various valuable compounds. This study, for the first time, examined the effects of tween 40 addition on $\mathrm{L}$-ornithine production and evaluated the fundamental mechanisms responsible for L-ornithine overproduction in C. glutamicum. Improvement of the thiamine biosynthesis pathway and attenuation of the biotin uptake system discovered using a total proteomics analysis were putatively associated with the increased production of L-ornithine. Interestingly, overexpression of CgS9114_09558 and deletion of CgS9114_13845, CgS9114_02593, and CgS9114_02058, proteins with higher expression multiples derived from the total proteomics analysis, further improved L-ornithine production in C. glutamicum Orn8. This study provides new support for the hypothesis that tween 40 addition can be used for the inducement of amino acid production. C. glutamicum is an excellent model organism for producing L-glutamate and L-glutamate-derived products including L-ornithine, -citrulline, and L-arginine. We believe that the metabolic engineering strategies reported in this work can be applied to constructing strains that will efficiently generate these products.

\begin{tabular}{|c|c|c|c|}
\hline Strains & $\begin{array}{l}\text { Cell biomass } \\
\left(O D_{600}\right)\end{array}$ & $\begin{array}{l}\text { L-ornithine } \\
\text { accumulation } \\
\text { (g/L) }\end{array}$ & $\begin{array}{l}\text { L-ornithine/cell } \\
\text { biomass }\left(\mathrm{OD}_{600}\right)\end{array}$ \\
\hline orn8 & $14.45 \pm 0.35$ & $19.58 \pm 0.42$ & 1.36 \\
\hline orn17 & $15.35 \pm 0.15$ & $17.66 \pm 0.36$ & 1.15 \\
\hline orn18 & $13.95 \pm 0.10$ & $20.28 \pm 0.53$ & 1.45 \\
\hline orn19 & $14.78 \pm 0.18$ & $17.81 \pm 0.68$ & 1.21 \\
\hline orn20 & $14.23 \pm 0.53$ & $22.01 \pm 0.40$ & 1.55 \\
\hline orn21 & $14.40 \pm 0.05$ & $20.79 \pm 0.11$ & 1.44 \\
\hline orn22 & $15.85 \pm 0.75$ & $22.52 \pm 0.49$ & 1.42 \\
\hline orn23 & $15.08 \pm 0.73$ & $21.86 \pm 0.08$ & 1.45 \\
\hline orn24 & $15.45 \pm 0.05$ & $21.84 \pm 0.91$ & 1.41 \\
\hline orn25 & $14.20 \pm 0.35$ & $18.87 \pm 0.55$ & 1.33 \\
\hline orn26 & $14.33 \pm 0.28$ & $17.18 \pm 0.17$ & 1.20 \\
\hline orn27 & $14.35 \pm 0.60$ & $16.93 \pm 0.42$ & 1.18 \\
\hline orn28 & $14.88 \pm 0.03$ & $23.83 \pm 0.19$ & 1.60 \\
\hline orn29 & $14.58 \pm 0.13$ & $25.46 \pm 0.23$ & 1.75 \\
\hline Orn30 & $15.43 \pm 0.28$ & $25.88 \pm 0.79$ & 1.68 \\
\hline
\end{tabular}

Fermentations were performed at $250 \mathrm{rpm}$ for $72 \mathrm{~h}$, and the initial glucose concentration was $100 \mathrm{~g} / \mathrm{L}$

Results are the means \pm standard deviations in three individual experiments

\section{Methods}

\section{Strains and plasmids}

Corynebacterium glutamicum Orn8, a L-ornithine producing strain constructed in our previous study [18, 36], derived from C. glutamicum S9114 was applied for strain development. Engineered strains and the plasmids used and developed in this study are listed in Table 3. For gene cloning and manipulation, E. coli DH5 $\alpha$ was employed as the host. Common mediums such as LB, LBG, LBHIS and et al. were used to genetic engineering of C. glutamicum.

\section{Strain cultivation and shake flask fermentation}

For the cultivation of engineered strains and shake flask fermentations, a bath culture method was performed as described previously $[15,16]$. Polyoxyethylene sorbitan monopalmitate (Tween 40) was added to the shake flask in the fermentation prophase.

\section{Protein extraction and trypsin digestion}

After being treated with tween 40 for $4 \mathrm{~h}$, cells were collected at $12 \mathrm{~h}$ by centrifugation $\left(5000 \times g\right.$ at $4{ }^{\circ} \mathrm{C}$ for $10 \mathrm{~min})$. Cells without tween 40 treatment were used as a control. Cell pellets were washed twice using cold deionized water. Subsequently, samples were resuspended in lysis buffer, containing $8 \mathrm{M}$ urea and $1 \%$ protease inhibitor cocktail, and then the turbid liquid was sonicated three times using a high intensity ultrasonic processor (Scientz). The residual debris was removed by centrifugation $\left(12,000 \times g\right.$ at $4{ }^{\circ} \mathrm{C}$ for $\left.10 \mathrm{~min}\right)$. After centrifugation, the lysate supernatant was identified as the crude protein sample and the protein concentration was determined using a BCA kit according to the manufacturer's instructions.

An appropriate amount of protein solution was used for trypsin digestion. At first, the protein solution was diluted to $5 \mathrm{mM}$ by using dithiothreitol and incubated at $56{ }^{\circ} \mathrm{C}$ for $30 \mathrm{~min}$. Then, the solution was alkylated with $11 \mathrm{mM}$ iodoacetamide for $15 \mathrm{~min}$ and protected from light and held at room temperature. Furthermore, the protein solution was diluted to a urea concentration of less than $2 \mathrm{M}$ by adding the appropriate amount of triethylamine borane. Finally, trypsin was added at a trypsin-to-protein mass ratio of 1:50 for the first overnight-digestion and with a trypsin-to-protein mass ratio of 1:100 for a second $4 \mathrm{~h}$-digestion.

\section{Peptide labeling}

After trypsin digestion, the randomly interrupted peptide fragments were desalted using a Strata X C18 SPE column (Phenomenex) and vacuum dried. Peptide fragments were resuspended in a $0.5 \mathrm{M}$ triethylamine borane solution and labeled using a TMT kit according to the manufacturer's protocol. Next, the thawed TMT reagent was briefly reconstituted in acetonitrile solution. Then, 
Table 3 Strains and plasmids used in this study

\begin{tabular}{|c|c|c|}
\hline Strain/plasmid & Characteristic & Source \\
\hline \multicolumn{3}{|l|}{ Strain } \\
\hline E. coli DH5a & Clone host strain & Transgen \\
\hline Orn8 & C. glutamicum S9114 with deletion of argF, ncgl1221, argR, putP, attenuation of odhA, and overexpression of lysE & Lab stock \\
\hline Orn17 & Orn8 carrying expression vector pEC-XK99E & This study \\
\hline Orn18 & Orn8 carrying expression vector pEC-CgS09558 & This study \\
\hline Orn19 & Orn8 carrying expression vector pEC-CgS14252 & This study \\
\hline Orn20 & Orn8 with $P_{\text {tac }}$ promoter inserted in front of CgS9114_09558 & This study \\
\hline Orn21 & Orn8 with $P_{\text {tac }}$ promoter inserted in front of CgS9114_14252 & This study \\
\hline Orn22 & Orn8 with deletion of CgS9114_13845 & This study \\
\hline Orn23 & Orn8 with deletion of CgS9114_02593 & This study \\
\hline Orn24 & Orn8 with deletion of CgS9114_02058 & This study \\
\hline Orn25 & Orn8 with deletion of CgS9114_14352 & This study \\
\hline Orn26 & Orn8 with deletion of CgS9114_04952 & This study \\
\hline Orn27 & Orn8 with deletion of CgS9114_14497 & This study \\
\hline Orn28 & Orn8 with deletion of CgS9114_13845 and CgS9114_02593 & This study \\
\hline Orn29 & Orn8 with deletion of CgS9114_13845, CgS9114_02593 and CgS9114_02058 & This study \\
\hline Orn30 & Orn8 with deletion of CgS9114_13845, CgS9114_02593, and CgS9114_02058; overexpression of CgS9114_09558 & This study \\
\hline \multicolumn{3}{|l|}{ Plasmid } \\
\hline pK18mobsacB & Mobilizable vector, allows for selection of double crossover in C. glutamicum, $\mathrm{Km}^{\mathrm{R}}$, sacB & {$[16]$} \\
\hline pEC-XK99E & A shuttle expression vector, $\mathrm{Km}^{\mathrm{R}}$ & Lab stock \\
\hline pEC-CgS14252 & A derivative of pEC-XK99E, harboring CgS9114_14252 gene from C. glutamicum S9114 under $\mathrm{P}_{\text {eftu }}$ promoter & This study \\
\hline pEC-CgS09558 & A derivative of pEC-XK99E, harboring CgS9114_09558 gene from C. glutamicum S9114 under $\mathrm{P}_{\text {eftu }}$ promoter & This study \\
\hline pK18-P tac $-C g S 09558$ & A derivative of pK18mobsacB, harboring $P_{\text {tac }}-C g$ S09558 fragment & This study \\
\hline pK18-P tac $-C g S 14252$ & A derivative of pK18mobsacB, harboring $\mathrm{P}_{\text {tac }}$-CgS14252 fragment & This study \\
\hline pK18- $\triangle$ CgS13845 & A derivative of pK18mobsacB, harboring $\triangle$ CgS9114_13845 fragment & This study \\
\hline pK18- $\triangle$ CgS02593 & A derivative of pK18mobsacB, harboring $\triangle C g S 9114 \_02593$ fragment & This study \\
\hline pK18- $\triangle$ CgS02058 & A derivative of pK18mobsacB, harboring $\triangle C g S 9114 \_02058$ fragment & This study \\
\hline pK18- $\Delta$ CgS14352 & A derivative of pK18mobsacB, harboring $\triangle$ CgS9114_14352 fragment & This study \\
\hline pK18- $\Delta$ CgS04952 & A derivative of pK18mobsacB, harboring $\triangle C g S 9114$ _04952 fragment & This study \\
\hline $\mathrm{pK} 18-\triangle \operatorname{CgS} 14497$ & A derivative of pK18mobsacB, harboring $\triangle C g S 9114$ _ 14497 fragment & This study \\
\hline
\end{tabular}

Superscript " $\mathrm{R}$ " indicates resistance to the following antibiotics: Km kanamycin

the TMT solution and peptide fragment mixtures were incubated for $2 \mathrm{~h}$ at room temperature, desalted, and dried by vacuum freezing.

\section{HPLC fractionation and LC-MS/MS analysis}

High pH reverse-phase HPLC using an Agilent 300Extend C18 column $(5 \mu \mathrm{m}$ particles, $4.6 \mathrm{~mm}$ ID, $250 \mathrm{~mm}$ length) was employed for the fractionation of tryptic peptides fractions. Peptides were first separated into 60 fractions using acetonitrile $(\mathrm{pH} 9.0)$ with a gradient of $8 \%$ to $32 \%$ over $60 \mathrm{~min}$. Subsequently, the peptides were mixed into 18 fractions and dried by vacuum freezing.

After dissolving them in $0.1 \%$ formic acid (solvent A), the peptide fractions were separated using an EASY-nLC 1000 UPLC system. Then, the peptides were injected into NSI ion source for ionization, followed by tandem mass spectrometry (MS/MS) analysis in Orbitrap FusionTM TribridTM (Thermo).

\section{Database search and bioinformatics analysis}

The resulting MS/MS data were processed using the Maxquant search engine (v.1.5.2.8). Tandem mass spectra were searched against the UniProt C. glutamicum database. A reverse decoy database search strategy was employed to evaluate the fault rate for peptide identification. The specific parameters were listed as follows: (1) enzyme, trypsin allowing up to 2 missing cleavages; (2) protein level FDR $\leq 1 \%$; (3) peptide length $\geq 7$ aa; (4) unique peptides $\geq 2$; (5) contaminants, trypsin; (6) protein modification. Carbamidomethyl on Cys was specified as a fixed modification and oxidation on Met was specified as a variable modification. Subsequently, proteins with an 
average ratio $>1.2$-fold increase or decrease were confidently considered as the differentially expressed proteins. Gene Ontology (GO) annotation of the total proteins was derived from the UniProt-GOA database (www. http:// $w w w . e b i . a c . u k / G O A / /)$. If some identified proteins were not annotated by the UniProt-GOA database, the InterProScan software was employed for GO annotation of those proteins. The Kyoto Encyclopedia of Genes and Genomes (KEGG) database was used to annotate and identify enriched pathways. These pathways were classified into hierarchical categories according to the KEGG website. We first collated all the categories obtained after enrichment along with their P values, and then filtered for those categories which were at least enriched in one of the clusters with a $P$ value $<0.05$. This filtered $P$ value matrix was transformed by the function $\mathrm{x}=-\log 10$ (P value).

\section{DNA manipulation and strain construction}

For the genetic engineering of genes in C. glutamicum, a suicide vector pK18mobsacB and expression plasmid pEC-XK99E based standard method was performed as described previously [37-39]. The primers used in this work are listed in Additional file 3: Table S3.

\section{Measurement of cell growth and metabolites concentration}

The biomass was monitored by measuring the $\mathrm{OD}_{600}$ using a microplate reader (BioTek Instruments, Winooski, VT, USA) after dissolving $\mathrm{CaCO}_{3}$ in $0.125 \mathrm{~mol} / \mathrm{L}$ $\mathrm{HCl}$. The L-ornithine titer was measured by colorimetry using ninhydrin as described previously [40, 41]. An SBA-40C biosensor (developed by Biology Institute of Shandong Academy of Sciences) was employed for glucose analysis in fermentation liquid [42]. To increase the reliability of measurements, samples were collected from three parallel experiments in order to calculate average values and standard deviations.

\section{Supplementary information}

Supplementary information accompanies this paper at https://doi. org/10.1186/s12934-019-1272-0.

Additional file 1: Table S1. The profiles of whole protein information identified by MS.

Additional file 2: Table S2. Differentially expressed protein statistics induced by tween 40 addition.

Additional file 3: Table S3. The profiles of all primers used in this study.

\section{Acknowledgements}

We thank Dr. Zhong-Gui Mao and Dr. Li-Ming Liu for providing strains Corynebacterium glutamicum S9114. We would like to thank Editage (www. editage.cn) for English language editing.

\section{Authors' contributions}

YJ conducted the experiments, XLC participated in the research, BZ planned, analyzed and interpreted data, and wrote the manuscript; All authors read and approved the final manuscript.

\section{Funding}

This work was supported by grants from the National Natural Science Foundation of China (31960014 and 31660019).

\section{Availability of data and materials}

Gene sequences used in this project are from Genbank (http://www.ncbi.nlm. nih.gov/) and the material and data supporting their findings can be found in the main paper and the additional file.

\section{Ethics approval and consent to participate}

No human participants were performed in this study.

\section{Informed consent}

Informed consent was obtained from all individual participants included in the study.

\section{Competing interests}

The authors declare that they have no competing interests.

\section{Author details}

${ }^{1}$ College of Bioscience and Engineering, Jiangxi Engineering Laboratory for the Development and Utilization of Agricultural Microbial Resources, Jiangxi Agricultural University, Nanchang 330045, China. ${ }^{2}$ College of Life Science, Jiangxi Normal University, Nanchang 330022, China.

Received: 12 September 2019 Accepted: 16 December 2019 Published online: 06 January 2020

References

1. Rathi S, Taneja S. Terminating and episode of overt hepatic encephalopathy: L-ornithine-L-aspartate may have some role. Hepatology. 2018;67:797.

2. Mitsuhashi S. Current topics in the biotechnological production of essential amino acids, functional amino acids, and dipeptides. Curr Opin Biotechnol. 2014;26:38-44.

3. Huang K, Mu W, Zhang T, Jiang B, Miao M. Cloning, expression, and characterization of a thermostable l-arginase from Geobacillus thermodenitrificans NG80-2 for L-ornithine production. Biotechnol Appl Biochem. 2016;63:391-7

4. Lee YJ, Cho JY. Genetic manipulation of a primary metabolic pathway for L-ornithine production in Escherichia coli. Biotechnol Lett. 2006;28:1849-56.

5. Qin J, Zhou YJ, Krivoruchko A, Huang M, Liu L, Khoomrung S, Siewers V, Jiang B, Nielsen J. Modular pathway rewiring of Saccharomyces cerevisiae enables high-level production of L-ornithine. Nat Commun. 2015:6:8224.

6. Kim SY, Lee J, Lee SY. Metabolic engineering of Corynebacterium glutamicum for the production of L-ornithine. Biotechnol Bioeng. 2015;112:416-21.

7. Mamat U, Wilke K, Bramhill D, Schromm AB, Lindner B, Kohl TA, Corchero $J$, Villaverde A, Schaffer L, Head SR. Detoxifying Escherichia coli for endotoxin-free production of recombinant proteins. Microb Cell Fact. 2015;14:57

8. Luo X, Reiter MA, d'Espaux L, Wong J, Denby CM, Lechner A, Zhang Y, Grzybowski AT, Harth S, Lin W. Complete biosynthesis of cannabinoids and their unnatural analogues in yeast. Nature. 2019;567:123.

9. Guo J, Suastegui M, Sakimoto KK, Moody VM, Xiao G, Nocera DG, Joshi NS. Light-driven fine chemical production in yeast biohybrids. Science. 2018:362:813-6.

10. Yu T, Zhou YJ, Huang M, Liu Q, Pereira R, David F, Nielsen J. Reprogramming yeast metabolism from alcoholic fermentation to lipogenesis. Cell. 2018;174:1549-58.

11. Hwang $\mathrm{G}-\mathrm{H}$, Cho J-Y. Enhancement of L-ornithine production by disruption of three genes encoding putative oxidoreductases in Corynebacterium glutamicum. J Ind Microbiol Biotechnol. 2014;41:573-8. 
12. Becker J, Wittmann C. A field of dreams: lignin valorization into chemicals, materials, fuels, and health-care products. Biotechnol Adv. 2019;37:107360.

13. Jeandet P, Sobarzo-Sanchez E, Clement C, Nabavi SF, Habtemariam S, Nabavi SM, Cordelier S. Engineering stilbene metabolic pathways in microbial cells. Biotechnol Adv. 2018;36:2264-83.

14. Kim HT, Khang TU, Baritugo KA, Hyun SM, Kang KH, Jung SH, Song BK, Park K, Oh MK, Kim GB, Kim HU, Lee SY, Park SJ, Joo JC. Metabolic engineering of Corynebacterium glutamicum for the production of glutaric acid, a C5 dicarboxylic acid platform chemical. Metab Eng. 2019;51:99-109.

15. Zhang B, Ren L, Yu M, Zhou Y, Ye B. Enhanced L-ornithine production by systematic manipulation of $L$-ornithine metabolism in engineered Corynebacterium glutamicum S9114. Bioresour Technol. 2017;250:60-8.

16. Zhang B, Yu M, Zhou Y, Li Y, Ye B. Systematic pathway engineering of Corynebacterium glutamicum S9114 for L-ornithine production. Microb Cell Fact. 2017;16:158

17. Zhang B, Yu M, Wei WP, Ye BC. Optimization of L-ornithine production in recombinant Corynebacterium glutamicum $\$ 9114$ by cg3035 overexpression and manipulating the central metabolic pathway. Microb Cell Fact. 2018;17:91.

18. Zhang B, Gao G, Chu XH, Ye BC. Metabolic engineering of Corynebacterium glutamicum $\mathrm{S} 9114$ to enhance the production of L-ornithine driven by glucose and xylose. Bioresour Technol. 2019;284:204-13.

19. Jensen JV, Eberhardt D, Wendisch VF. Modular pathway engineering of Corynebacterium glutamicum for production of the glutamate-derived compounds ornithine, proline, putrescine, citrulline, and arginine. J Biotechnol. 2015;214:85-94.

20. Jiang L-Y, Chen S-G, Zhang Y-Y, Liu J-Z. Metabolic evolution of Corynebacterium glutamicum for increased production of L-ornithine. BMC Biotechnol. 2013;13:47

21. Shu Q, Xu M, Li J, Yang T, Zhang X, Xu Z, Rao Z. Improved L-ornithine production in Corynebacterium crenatum by introducing an artificial linear transacetylation pathway. J Ind Microbiol Biotechnol. 2018;45:393-404.

22. Lu J, Li X, Yang R, Zhao J, Qu Y. Tween 40 pretreatment of unwashed water-insoluble solids of reed straw and corn stover pretreated with liquid hot water to obtain high concentrations of bioethanol. Biotechnol Biofuels. 2013:6:159.

23. Nakayama Y, Hashimoto K, Sawada Y, Sokabe M, Kawasaki H, Martinac B. Corynebacterium glutamicum mechanosensitive channels: towards unpuzzling "glutamate efflux" for amino acid production. Biophys Rev. 2018:10:1359-69.

24. Chen M, Chen X, Wan F, Zhang B, Chen J, Xiong Y. Effect of tween 40 and dtsR1 on L-arginine overproduction in Corynebacterium crenatum. Microb Cell Fact. 2015;14:119.

25. Takahashi C, Shirakawa J, Tsuchidate T, Okai N, Hatada K, Nakayama $\mathrm{H}$, Tateno T, Ogino C, Kondo A. Robust production of gamma-amino butyric acid using recombinant Corynebacterium glutamicum expressing glutamate decarboxylase from Escherichia coli. Enzyme Microb Technol. 2012;51:171-6.

26. Seiki T, Manami T, Akinobu U, Akinori M, Tetsuhiro M, Satoshi M, Masato I. Development of fatty acid-producing Corynebacterium glutamicum strains. Appl Environ Microbiol. 2013;79:6776-83.

27. Matsushima Y, Hirasawa T, Shimizu H. Enhancement of 1,5-diaminopentane production in a recombinant strain of Corynebacterium glutamicum by tween 40 addition. J Gen Appl Microbiol. 2016;62:42-5.
28. Kim J, Hirasawa T, Sato Y, Nagahisa K, Furusawa C, Shimizu H. Effect of odhA overexpression and odhA antisense RNA expression on Tween40-triggered glutamate production by Corynebacterium glutamicum. Appl Microbiol Biotechnol. 2009;81:1097-106.

29. Asakura Y, Kimura E, Usuda Y, Kawahara Y, Matsui K, Osumi T, Nakamatsu T. Altered metabolic flux due to deletion of odhA causes L-glutamate overproduction in Corynebacterium glutamicum. Appl Environ Microbiol. 2007;73:1308-19.

30. Cao Y, Duan Z, Shi Z. Effect of biotin on transcription levels of key enzymes and glutamate efflux in glutamate fermentation by Corynebacterium glutamicum. World J Microbiol Biotechnol. 2014;30:461-8.

31. Kim J, Hirasawa T, Saito M, Furusawa C, Shimizu H. Investigation of phosphorylation status of Odhl protein during penicillin- and Tween 40-triggered glutamate overproduction by Corynebacterium glutamicum. Appl Microbiol Biotechnol. 2011;91:143-51.

32. Eikmanns BJ, Blombach B. The pyruvate dehydrogenase complex of Corynebacterium glutamicum: an attractive target for metabolic engineering. J Biotechnol. 2014;192(Part B):339-45.

33. Wen J, Bao J. Engineering Corynebacterium glutamicum triggers glutamic acid accumulation in biotin-rich corn stover hydrolysate. Biotechnol Biofuels. 2019;12:86.

34. Wang X, Khushk I, Xiao Y, Gao Q, Bao J. Tolerance improvement of Corynebacterium glutamicum on lignocellulose derived inhibitors by adaptive evolution. Appl Microbiol Biotechnol. 2018;102:377-88.

35. Schultz C, Niebisch A, Gebel L, Bott M. Glutamate production by Corynebacterium glutamicum: dependence on the oxoglutarate dehydrogenase inhibitor protein Odhl and protein kinase PknG. Appl Microbiol Biotechnol. 2007;76:691-700.

36. Zhang B, Yu M, Zhou Y, Ye BC. Improvement of L-ornithine production by attenuation of argF in engineered Corynebacterium glutamicum 59114. AMB Express. 2018;8:26.

37. Shäfer A, Tauch A, Jäger W, Kalinowski J, Tierbach G, Pühler A. Small mobilizable multi-purpose cloning vectors derived from the Escherichia coli plasmids pK18 and pK19: selection of defined deletions in the chromosome of Corynebacterium glutamicum. Gene. 1994;145:69-73.

38. Zhang B, Wan F, Qiu Y, Chen X, Tang L, Chen J, Xiong Y. Increased L-arginine production by site-directed mutagenesis of $\mathrm{N}$-acetyl-L-glutamate kinase and proB gene deletion in Corynebacterium crenatum. Biomed Environ Sci. 2015;28:864-74.

39. Zhang B, Ye BC. athway engineering in Corynebacterium glutamicum S9114 for 5-aminolevulinic acid production. 3 Biotech. 2018;8:247.

40. Rosen H. A modified ninhydrin colorimetric analysis for amino acids. Arch Biochem Biophys. 1957;67:10-5.

41. Jiang L-Y, Zhang Y-Y, Li Z, Liu J-Z. Metabolic engineering of Corynebacterium glutamicum for increasing the production of L-ornithine by increasing NADPH availability. J Ind Microbiol Biotechnol. 2013;40:1143-51.

42. Qiu Z, Gao Q, Bao J. Engineering Pediococcus acidilactici with xylose assimilation pathway for high titer cellulosic I-lactic acid fermentation. Bioresour Technol. 2018:249:9-15.

\section{Publisher's Note}

Springer Nature remains neutral with regard to jurisdictional claims in published maps and institutional affiliations.

Ready to submit your research? Choose BMC and benefit from

- fast, convenient online submission

- thorough peer review by experienced researchers in your field

- rapid publication on acceptance

- support for research data, including large and complex data types

- gold Open Access which fosters wider collaboration and increased citations

- maximum visibility for your research: over 100M website views per year

At BMC, research is always in progress.

Learn more biomedcentral.com/submissions 